\title{
The Ling Sound Test: What is its Relevance in the New Zealand Classroom?
}

\author{
Scott McDonnell
}

\section{Practice Paper}

Keywords: aural skills, hearing impairment, Ling Sound Test, speech

\begin{abstract}
Daniel Ling created the Ling Sound Test (auditory assessment tool) and it was first published in the book titled Speech and the Hearing-Impaired Child: Theory and Practice (Ling,1976). The philosophy behind Ling's sound test is to use a range of speech sounds that largely represents the speech spectrum from 250-8000 Hz using isolated phonemes to target low, middle and high-frequency sounds (Smiley, 2004). Ling's phoneme sounds are [m], [ah], [oo], [ee], [sh] and [s]. The test is not a test of comprehension: it is used for checking the aural skills of detection, discrimination and identification (Smiley, 2004). A wide range of people can use this tool including audiologists, speech therapists, teachers of the deaf, classroom teachers and parents. It is a quick and accurate assessment tool that can be exercised with users of cochlear implants, hearing aids or with no amplification at all. It has a variety of applications, and can be used with a wide range of ages or needs. The Ling Sound Test is used worldwide (English speaking) and is used daily by teachers of the deaf based at van Asch Deaf Education Centre (Christchurch) and Kelston Deaf Education Centre (Auckland).
\end{abstract}

\section{Historical and Conceptual Information}

Ling was born in England in 1926. His initial employment was in the Royal Air Force service with radar and communications. This provided a great communication foundation for his profession in education and understanding of audiological devices. Ling had his first professional training as a teacher at St. John's College, York, through the Education and Audiology of the Deaf course at Manchester University (Ling, 1989). He carried out research in various areas of hearing, speech and educational audiology at Cambridge Institute of Education and later on in the Department of Psychology at Reading University (Ling, 1989). In 1963, he moved to Canada and continued to work in the same field with his wife. Together they founded the McGill University Project for Deaf Children and brought a focus and research application to early sound development in early intervention programmes. They supported the importance of parent guidance and participation which are fundamental to habituation. Serving as the Director of Deaf Education, Ling used his knowledge of technology to build and modify hearing aids, resulting in more profoundly-deaf children being educated in regular school classes (Dornan, 2012). Over many decades Ling had considerable influence on the development of education and rehabilitation for children with hearing loss (Fitzpatrick, 2010).

The methodology of Ling's system is based on a developmental model. Ling believed that hearing is a first order event for the development of spoken communication and literacy skills (Dornan, 2012). His model has five hierarchical broad stages which overlap slightly, each with its own order of development. As Locke (2010) points out "it is important that speech sounds are learned in syllables, followed by practice at a phonetic level, and then used in communicative speech in a timely manner to provide meaning" (p.1 ). The Ling System also focuses on early identification and intervention. His system considers a child must be identified and aided as early as possible (Perigoe \& Paterson, 2015) From his research, Ling designed the sound test which was intended to be a simple and easy-to-administer test for detection, however, its simplicity does not counteract its validity (Ling, 1989). The sounds selected represent significant cues in each frequency to help the administrator check a childs detection and ability to produce the sound. This allows adults to monitor children's hearing or audio devices daily in an accurate manner through the Ling Sound Test (Easterbrooks \& Estes, 2007).

These sounds range from $250 \mathrm{~Hz}$ to $8000 \mathrm{~Hz}$ : the [m] sound as in me is a low frequency sound $(250 \mathrm{~Hz})$; the [oo] as in two is a middle frequency sound 
$(500 \mathrm{~Hz})$; the [ah] sound as in aha is a high frequency sound $1000 \mathrm{~Hz}$ and the [ee] sound as in she is a high frequency sound $(2000 \mathrm{~Hz})$. The [sh] as in fish is a high frequency sound $(2000 \mathrm{~Hz})$ and finally, the [s] sound as in us is a low intensity sound, but high frequency $(4000 \mathrm{~Hz})$ (Cole \& Flexer, 2010). As can be seen, the vowel sounds have strong, low frequency energy $(250-500 \mathrm{~Hz})$ and are powerful sounds in the English language. Moreover, "vowels carry 90\% of the energy of speech" ... "consonants carry only $10 \%$ of the energy of speech but $90 \%$ of the information needed to perceive the differences among the sounds" (Cole \& Flexer, 2010, p. 27). Consequently, both vowels and consonants need to be available to hear speech. The Ling Sound Test is a fast, efficient assessment to ensure there is access to the speech spectrum of intensities and frequencies.

The audiogram shown below illustrates where the sounds fall on the audiogram; most importantly is the red portion in the middle, which is often referred to as the 'speech banana' (Evergreen Speech and Hearing Clinic, 2013). This red area is a representation of where the sounds in speech fall in terms of pitch (frequency) and loudness (intensity).

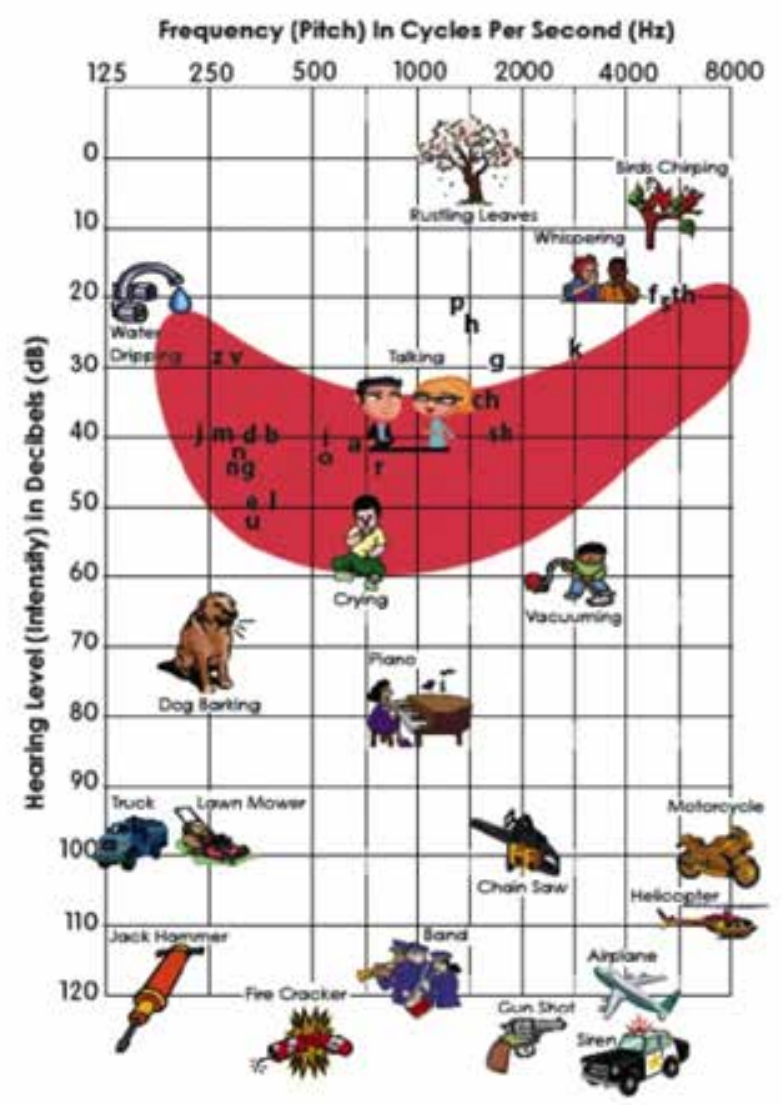

Image retrieved from:

http://everhear.com/understanding-your-audiogram/
The Ling Sound Test can be used with children of different ages and stages of auditory development. Mustard (2011) of Christchurch's Southern Cochlear Implant Programme (SCIP) notes that the hierarchy of auditory development begins with children becoming aware of sound. This is the first stage (detection). Next is attaching the meaning to sound and then understanding increasingly complex language (increasing the length of messages and understanding phrases and sentences of increasing grammatical complexity). Accordingly, this is how the Ling Sound Test can be utilised with a range of ages and stages. Detection (I can hear something) with young babies is observing to see if their eyes startle, stop what they are doing, or look in the direction of the sound (Mustard, 2011). Older children can be instructed to put a peg into a peg-board or throw a ball into a container each time they hear a sound (Mustard, 2011).

The next step is part of the identification stage. It involves the ability to discriminate between sounds. This is where the child can go from hearing a sound to knowing what they heard. Pointing to a sound card of the sound they have heard can do this. Lastly, by producing the sound they have heard shows that they can detect, discriminate and produce the sound. Usually all these tests are presented at conversational distance of one to two metres (Mustard, 2011). If children cannot access all of the Ling sounds or if their response to sounds changes, then there is a need to check to see if there is a change in their health, functioning of their amplification, or possibly a temporary or permanent deterioration with their hearing. All this is possible with daily checks and close monitoring.

The sound test is not limited to English-speaking individuals. It can also be used with non-English speaking populations. Countries such as Vietnam are utilising Ling's test but modified to their language. To see an example refer to this website address: http://trekhiemthinh.com/news/86/6-am-ling-6-lingsounds.html. MED-EL (leading manufacturer of audio equipment) produce the Ling Sound Test cards in Hindi, German, French, Spanish, Turkish and many others. These can be viewed at: http://www.medel. com/int/show2/index/id/284/title//?showdir=bridge/ soundcards\&. Furthermore, iTunes have produced an App labelled Ling 6 Sound Application which illustrates its use worldwide. Understandably, the test can be used in New Zealand with English being one of the three official languages.

The practice of the Ling Sound Test aligns with Bronfenbrenner's Ecological Systems Theory (Bronfenbrenner, 1979) because of its child-centred approach. Bronfenbrenner views the child as an active, developing individual engaging in reciprocal 
relationships with people in his or her environment (Shaffer, 2013). In this sense the child, other people, and the environment all play a role in contributing to the child's development. Bronfenbrenner's system has five layers which are the microsystem (such as the family or classroom), the mesosystem (which is two microsystems in interaction), the exosystem (external environments which indirectly influence development, e.g. parental workplace), the macrosystem (the larger socio-cultural context), and the chronosystem (the evolution of the external systems over time) (Shaffer, 2013). Performing the Ling Sound Test supports the child within their microsystem and mesosystem by checking that they have access to the full range of speech sounds. Additionally, accessing the speech sounds will provide language opportunities with the other systems.

Ling was likely to be influenced by Jerome Bruner's Scaffolding Theory in the early 1960s. Bruner, a cognitive psychologist first introduced the Scaffolding Theory in the late 1950s where he used this term to describe young children's oral language acquisition (Bakhurst \& Shanker, 2001). Bruner suggested that social interaction plays a fundamental role in the development of cognition in general and language in particular. Utilising Ling's sound test could be one aspect that might support a child's language development by checking a child's access to speech sounds. By monitoring their hearing levels, it may support access to meaningful language development, especially in the early years. This also connects to the Ling's focus with research application to early sound development in early intervention programmes.

\section{Relevance to New Zealand Policies and Practices}

The practice of utilising the Ling Sound Test currently fits with many of New Zealand's key documents and policies. These include the government strategy, Success for All - Every School, Every Child (Ministry of Education, 2010), New Zealand Curriculum (Ministry of Education, 2007), Te Whāriki (Ministry of Education, 1996), Collaboration for Success: Individual Education Plans (Ministry of Education, 2011) and the NZ Disability Strategy (Ministry of Health, 2001).

The Government's strategy, Success for All - Every School, Every Child (Ministry of Education, 2010) sets out the government's vision for a fully-inclusive education system by 2014. This includes students with sensory needs. From 2012, students with a sensory impairment (hearing or vision) who receive

1 The Ongoing Resourcing Scheme provides support for students with high or very high special educational needs. support from the Ongoing Resourcing Scheme (ORS) ${ }^{1}$ have their teaching component of ORS paid to their sensory school. For the deaf, these are van Asch and Kelston Deaf Education Centres. Teachers of the deaf from these centres are required to check their students on each visit with the Ling Sound Test to ensure they are within their normal range of hearing. The test also checks that any assistive technologies like cochlear implants or hearing aids are functioning optimally.

One of the guiding principles that underpin The New Zealand Curriculum (Ministry of Education, 2007) is inclusion. The document states that "students' identities, languages, abilities and talents are recognised and affirmed and that their learning needs are addressed" (p. 9). The Ling Sound Test ensures that a student has the ability to hear as optimally as possible and this practice will support part of their learning needs.

Likewise, the Ling Sound Test supports the early childhood curriculum, Te Whāriki (Ministry of Education, 1996). This document points out that "language is a vital part of communication. In early childhood, one major cultural task for children is to develop competence in and understand language" (p. 72). In addition, Marschark (2007), who is a world leader in deaf education and research, points out that "deaf children's access to language during the critical stages of development (the first two to three years) has a variety of consequences in social, language, and academic areas" (p. 23). Once more, using the Ling Sound Test daily is easy and efficient. It will ensure amplification devices, especially during their early use, are working correctly and if not, something can be done about it so the child is not missing out on fundamental language experiences.

With the implementation of the government strategy, Success for All - Every School, Every Child (Ministry of Education 2010), "the majority of deaf children attend their local mainstream school, some with support from teacher aides and/or peripatetic teachers" (World Association of Sign Language Interpreters, 2013). Therefore, it is imperative that when these students are receiving their education in these settings, they are receiving equitable and quality education. The Ministry of Education document Collaboration for Success: Individual Education Plans (Ministry of Education, 2011) which provides guidance on supporting students with special education needs, notes that teachers need to "draw on a range of effective assessment approaches, using the principles of assessment for learning' (p. 4). Ling's sound test would be one of the effective assessment tools to be used to ensure their learning needs are being met. 
The NZ Disability Strategy (Ministry of Health, 2001) sets out a framework for government agencies (including schools) when making policy or providing services that impact on disabled people. Goals 3.2 and 3.4 are particularly relevant to deaf students in New Zealand schools. These goals are:

- support the development of effective communication by providing access to education in New Zealand Sign Language, communication technologies and human aides

- ensure that disabled students, families, teachers and other educators have equitable access to the resources available to meet their needs.

Using the Ling Sound Test ensures that students are able to have equitable access to education by checking that assistive technology, such as cochlear implants, are working optimally and that hearing is not changing over time. If a student's hearing is decreasing, then the test will pick up on this and next steps can be looked at to support that student, family and education setting.

\section{Implementation of the Ling Sound Test}

Since its establishment in 1967, many foundations, specialising practices and schools have modified/ adapted the sound test to align with their beliefs or type of practice. However, the basic fundamentals of the test have not changed. It takes time to establish and administer the Ling Sound Test effectively. Time is needed to demonstrate to a child what is required or needed. Also, consideration of the child's age and stage of development needs to be taken into account. Once this has been set up, a baseline is created to what is expected on a daily occurrence.

According to Cochlear (2013) and Duncan et al., (2010), the Ling Sound Test is implemented in the following way:

1. Demonstrate what the administrator expects of the child being tested. This can be:

a) Detection: when a sound is heard, a child could raise a hand, clap or drop something into a box.

b) Discrimination: where a child discriminates two or more sounds as being the same or different.

c) Identification: where a child points to a picture of the sound or produces the sound they heard.

2. Sit or stand 1 metre ( 3 feet approximately) from a child while being next to or behind the child. This ensures there are no visual cues for the child.

3. Firstly, say the sounds at a typical conversational level (50-65 dB) $20 \mathrm{~cm}$ away from the child. Once the child has responded to all the sounds increase to one metre distance. The six sounds need to be random and have varying pauses to ensure that no known pattern occurs, and lessens the chance of prediction by the child for a sound.

4. Increase distances to two and three metres. Record correct responses, any incorrect and/or no responses, and make notes that could be useful.

The one metre range is thought to be an average distance for a one-to-one conversation and three metres as a distance for a group setting (Ling, 2002). Over time, tracking the data of the child's responses will create a baseline. A simple recording sheet to collect the data is sufficient. This baseline will allow the administrator to know if a child's responses are out of the normal parameters.

The goal of the practice is to check that a child's entire auditory system is working correctly. It also checks hearing aid amplification or cochlear implants. After a baseline has been established, the Ling Sound Test can then track any changes in the child's hearing and/or audio-equipment.

To learn how to train, or what support is needed to administer the Ling Sound Test, there is a wealth of website information for parents or teachers to access. Key leading manufacturers of hearing assistive technology such as Cochlear and MED-EL have an abundance of information and resources. Many countries have different training programmes to learn how to implement the Ling Sound Test. Within a New Zealand context, according to audiologist Paul Peryman at van Asch Deaf Education Centre (personal communication, 2013), teachers of the deaf get trained with the test if they have not had experience with it. The training involves working with a mentor and observing and practising with the test. This is to ensure the test is being implemented correctly and results interpreted appropriately.

\section{Strengths and Limitations}

The Ling Sound Test is a fast, easily-administered test with high validity (Agung, Purdy \& Kitamura, 2005). Very little time is needed ( 5 minutes on average) to administer the test with instant results that need little analysing or interpretation. It can be used with a range of ages or needs. Once a baseline of assessment has been formed, changes can easily be identified and simple adjustments, such as flat batteries, can be rectified immediately. It can also be fun with a child, whereby teachers can have a role reversal and the child tests the adult (Couglan, RTD, personal communication, 2013). 
The Ling Sound Test can also assess other modern technologies like the F.M. listening system. This device is advocated for classroom use by the Ministry of Education (Ministry of Education, 2013) which aids to increase the speech signal (normally the class teacher's voice) in relation to background noise. This transmission happens on a reserved radio spectrum of 216 to $217 \mathrm{MHz}$ (Burke, 2010). A teacher could utilise the Ling Sound Test to check if the F.M. system is working correctly and optimally. From using the sounds, the teacher could adjust the settings on the microphone unit or its placement to maximise the system's potential. However, this is providing that the test has been administered firstly without the F.M., and understanding the system does have limitations.

A possible limitation of the Ling Sound Test within a New Zealand context could be considering the sh and s sounds are not part of the Māori language; Te Reo. If a child was fluent in Te Reo and did not speak English then it would be difficult to reproduce these sounds. This practice can still be used to check if the child can detect the sounds but discrimination and identification may be void. Other considerations when utilising the Ling Sound Test is if the student has complex needs such as a learning disability, speech and language impairment, or cognitive impairment. These students may have limited cognitive or metacognitive knowledge or skills to participate with the sound test (Evers \& Spencer, 2011).

The Ling Sound Test can be used by a variety of people, but this could also become a possible barrier to the validity of the test. Being untrained with the administration of the test, and perhaps different interpretations with information or results, could lead to conflicting results. This in turn may create confusion and possible disappointment. Sourcing correct information and seeking support from people who are trained with the test would increase the success of the implementation of the Ling Sound Test.

Another possible limitation of the Ling Sound Test is the limited calibrated method of sound delivery by the administrator. However, a limited study by Tenhaaf and Scollie (2005) focused on creating a calibrated, computer-assisted version of the Ling Sound Test to be at the correct frequencies and intensities. They compared it to an everyday voice and their conclusion was the test still "appears to fall between moderate and good test-retest reliability" (2005, p. 45). Equally, Ling states that "while the pitches of voices may differ, the components of the sounds that permit the identification and comprehension of speech sounds are sufficiently close for the purpose of the basic test" (cited in Estabrooks \& Birkenshaw-Fleming, 2003, p.227).
It can be determined, after examining the strengths and limitations of the Ling Sound Test, that the person administering the test should be trained in it: this will maximise the test effectiveness and reliability. According to Kelly-Campbell (Senior lecturer, Audiology, University of Canterbury), audiologists in New Zealand are trained with the Ling Sound Test (personal communication, 2013). They also have immense knowledge around audiometric equipment, diagnosing hearing problems, testing and interpreting results (Audiometry, 2013). However, daily testing is not a realistic or practical situation for an audiologist. Ling designed the test to be a daily, easily-administered test that has validity (Smiley, 2004). Teachers of the deaf, who are also trained with the test, should administer the test. They are more likely to have regular contact with children to test and monitor changes. Teachers of the deaf will also establish a working relationship with a child that will support the ease of the implementation of the test. It has been noted that parents can test their child but caution with validity may well be a concern with correct administration and interpretation of results.

Classroom teachers are another group which can use the Ling Sound Test. With implementation of New Zealand's Disability Strategy (Ministry of Health, 2001), the policy Success for All - Every School, Every Child (Ministry of Education, 2010) and the movement towards inclusive schools and classrooms, there now appears to be a need for classroom teachers to become trained with the Ling Sound Test. For students with hearing impairment in mainstream classrooms, it is imperative that they have access to adaptations such as visual prompts, curriculum modifications, assistive technology (e.g. FM. system), or specific physical locations to be within an operative hearing range of the teacher. The Ling Sound Test may possibly be part of this intervention response. For this reason, the Ling Sound Test can be administered by the classroom teacher providing that they have had training to administer the test.

\section{ADAPTATIONS}

Potential adaptations for accents with the Ling Sound Test could be considered with slight differences between production and spectral content of North American vowels (whom the test was originally devised for) and other English-speaking countries such as New Zealand and Australia (Agung et al., 2005). In 2005, a study was conducted targeting the appropriateness of the Ling sounds with an Australian accent. A brief questionnaire was given to clinicians in New South Wales who regularly used the Ling Sound Test. The questionnaire was utilised to determine how they administered and interpreted 
results. Out of the study's recommendations, the six sounds of [m], [ah], [oo], [ee], [sh] and [s] were endorsed (Agung et al., 2005). According to Christchurch audiologist, Mustard, (personal communication, 2013), there was a trend in New Zealand toward including 'or' as people thought that the North American 'ah' sounded more like our 'or'. However, it isn't currently considered necessary to check this additional sound. Hence, for a New Zealand population, it can be established that the six sounds are still valid sounds even with accent differences. Therefore, no adaptation is needed to Ling's six sounds.

When considering adaptations for Māori with the Ling Sound Test, it has already been noted that the high frequency sounds used with the test, $s$ and $s h$, are not in Te Reo. This needs deliberation when implementing the test. If the administrator wanted additional information other than detection, demonstration and teaching would need to be included. Adaptations for Māori as a culture, include discussing Te Pikinga ki Runga as a framework to be utilised (Macfarlane, 2009). This framework was created on the humanrights principles within the Treaty of Waitangi. This framework has three treaty principles: partnership, protection and participation. When considering these principles, communication, partnership, and being included are vital for Māori. Providing opportunities to learn how to administer the Ling Sound Test, including the family with on-going assessment whilst establishing a strong relationship, or making joint decisions should all be respected. Another possibility might be to find a Māori audiologist or a similarlytrained person to run the test.

There are considerations when using the Ling Sound Test with additional or special needs. Christchurch's audiologist Mustard uses the Ling Sound Test with special needs (personal communication, 2013): she states that if someone's speech is so inadequate that the tester doesn't think they could tell what sound the child is saying, they only use it as a detection task. Picture representations could be used but it may take longer and also involves another cognitive task. Generally, special needs children do a wait-listenrespond (stimulus-response) task. This would allow the tester to know that a child can hear the sound and respond accordingly. Similarly, some children with an autism spectrum disorder who find it difficult to respond to spoken language and have minimal spoken language, can still respond to the structure of the Ling task in the above manner. This is very useful because it still shows the audiologist that a person is able to hear across the frequencies for speech even if they can't use spoken language for communication.

\section{CONCLUSION}

In conclusion, through this critical analysis of the Ling Sound Test, it can be seen that the sound test has huge benefits to people who utilise it correctly and for whom it is being directed to. The Ling Sound Test is an accurate and quick assessment tool that can be exercised with people who are hearing-impaired, users of cochlear implants or hearing aids. It has a variety of applications which can be used for a wide range of ages, groups or needs. There are minimal limitations with its use other than what has been discussed. Perhaps this is why, since its establishment in 1967, it is still currently a popular and effective assessment tool.

\section{REFERENCES}

Agung, K., Purdy, S., \& Kitamura, C. (2005). The Ling Sound Test revisited. Australian and New Zealand Journal of Audiology, 27, (1), 33-41.

Audiometry (2013). In Wikipedia, the Free Encyclopaedia. Retrieved June 16th, 2013 from http://en.wikipedia.org/wiki/Audiometry

Bakhurst, D., \& Shanker, S. (2001). Jerome Bruner: Language, culture and self. California, US: SAGE Publications Ltd.

Bronfenbrenner, U. (1979). The ecology of human development: Experiments by Nature and Design. Cambridge, MA: Harvard University Press.

Burke, J. (2010). FM Systems. Retrieved 31st May, 2013 from http://deafness.about.com/cs/ educationgeneral/a/fmsystems.htm

Cochlear, (2013) The Ling-6 Sounds. Retrieved June 31 st, 2013 from http://www.cochlear.com/wps/ wcm/connect/intl/home/home

Cole, E., \& Flexer, C. (2010). Children with hearing loss: developing listening and talking, birth to six. San Diego, US: Plural Publishing Inc.

Dornan, D. (2012). The Ling consortium. Retrieved 19th May, 2013 from http://www. listeningandspokenlanguage.org/uploadedFiles/ Connect/Meetings/2012_Convention/Handouts/ SaSA_TheLingLegacy_Presentation1.pdf

Duncan, J., Kendrick, A., Ginnis, M.D., \& Perigoe, C. (2010). Auditory (re)habilitation teaching behavior rating scale. JARA, XLIII, 65-86.

Easterbrooks, E., \& Estes, E. (2007). Helping deaf and hard of hearing students to use spoken language. Thousand Oaks, CA: Corwin Press.

Estabrooks, W., \& Birkenshaw-Fleming, L. (2003). Songs for learning! Songs for life! Washington D.C.: AG Bell. 
Evergreen Speech and Hearing Clinic (2013). Understanding your audiogram. Retrieved June 16th, 2013 from http://everhear.com/ understanding-your-audiogram/

Evers, R., \& Spencer, S. (2011). Planning effective instruction for students with learning and behavior problems. USA: Pearson Education.

Fitzpatrick, E. (2010). Professional training in listening and spoken language - a Canadian perspective. The Volta Review: Alexander Graham Bell Association for the Deaf and Hard of Hearing, 110(2), 331-338.

Ling, D. (1976). Speech and the hearing-impaired child: Theory and practice. Washington, D. C.: A. G. Bell Association for the Deaf.

Ling, D. (1989). Foundations of spoken language for hearing-impaired children. Washington, D.C.: A. G. Bell Association for the Deaf.

Ling, D. (2002). The Ling six sound test. Proceedings of the 2002 Alexander Graham Bell Convention, St Louis, MO.

Locke, S. (2010). Rational: Ling's speech development model. Retrieved June 16th, 2013 from http:// stephalocke.weebly.com/uploads/8/0/6/7/8067547/ rational-lings_speech_development_model.docx

Macfarlane, S. (2009). Te pikinga ki runga: Raising possiblities. set: Research Information for Teachers, 2. $42-50$.

Marschark, M. (2007). Raising and educating a deaf child. Oxford: University Press.

Ministry of Education (1996). Te whàriki, he whàriki màtauranga mò ngà mokopuna o Aotearoa, Early Childhood Curriculum. Wellington: Learning Media Limited.

Ministry of Education (2007). The New Zealand Curriculum. Wellington: Learning Media Limited.

Ministry of Education (2010). Success for allevery school, every child. Retrieved June 11th, 2013 from http://www.minedu.govt.nz/ NZEducation/EducationPolicies/SpecialEducation/ OurWorkProgramme/SuccessForAll.aspx

Ministry of Education (2011). Collaboration for success: Individual education plans. Wellington: Learning Media Limited.

Ministry of Education (2013). Auditory processing disorder. Retrieved June 11th, 2013 from http://www.minedu.govt.nz/NZEducation/ EducationPolicies/SpecialEducation/ ServicesAndSupport/AssistiveTechnology/ AssistiveTechnologyFactsheets/ ATAuditoryProcessingDisorder.aspx
Ministry of Health. (2001). The New Zealand disability strategy. Wellington, New Zealand: Author.

Mustard, J. (2011). Auditory development. Retrieved from Power Point presentation on http:// specialistteaching.net.nz/mod/book/view. php? $i d=2821 \&$ chapterid $=2783$

Perigoe, C.B., \& Paterson, M.M. (2015). Understanding auditory development and the child with hearing loss. In D.T.Welling \& C.A.Ukstins (Eds.).

Fundamentals of audiology for the speech-language pathologist. (pp. 173-201). Burlington, MA: Jones and Bartlett Learning.

Shaffer, D. (2013). Development psychology: Childhood adolescence. U.S.A.: Cengage Learning.

Smiley, D. (2004). Using the Ling 6-sound test everyday. Retrieved from http://www. audiologyonline.com/articles/using-ling-6-soundtest-1087

Tenhaaf, J., \& Scollie, S. (2005). Normative threshold levels for calibrated, computer-assisted version of the Ling six-sound test. Canadian Acoustics; Vol. 33 No. 3. 44-45.

World Association of Sign Language Interpreters (WASLI) (2013). New Zealand. Retrieved 20th May, 2013 from http://www.wasli.org/files/ downloads/252_new\%20zealand\%20country\%20 report.pd

\section{Personal Communications}

Couglan, Cheryle. Resource Teacher of the Deaf at van Asch Deaf Education Centre. Christchurch, New Zealand.

Kelly-Campbell, Rebecca. Senior lecturer, Audiology, University of Canterbury. Christchurch, New Zealand.

Mustard, Jill. Audiologist at Christchurch's Southern Cochlear Implant Programme (SCIP). Christchurch, New Zealand.

Peryman, Paul. Audiologist at van Asch Deaf Education Centre. Christchurch, New Zealand. 


\section{AUTHOR PROFILE}

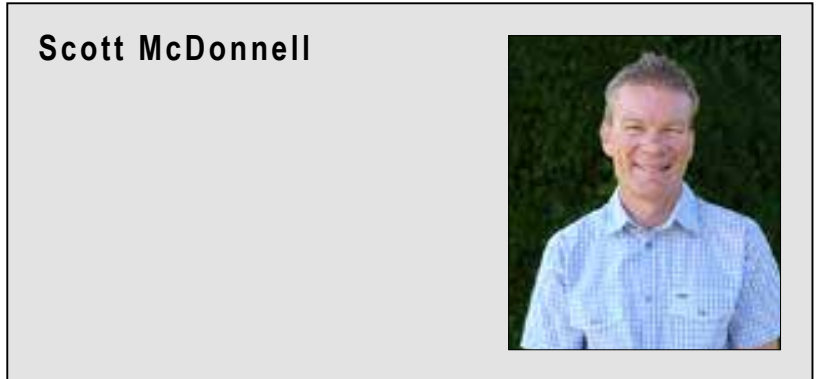

Scott McDonnell is currently employed by van Asch Deaf Education Centre in Christchurch. He is teaching in the high school base with Y9/10 students. He has also taught in a variety of mainstream primary schools with a wide range of age groups from NE to Y7. He completed a Postgraduate Diploma in Specialist Teaching (endorsed in Deaf and Hearing Impairment) last year and is studying for his Masters in Specialist Teaching in 2015.

\section{Email:}

smcdonnell168@vanasch.school.nz 